\title{
Cultivo da Microalga Chlorella Vulgaris em Fotobiorreator de Placas Planas e Produção de Ésteres por Transesterificação In Situ ${ }^{1}$
}

\author{
Valeria Ferreira Cavalcanti² ${ }^{2}$, Bruna Elise Sauer Leal ${ }^{3}$, Marcelo Real Prado ${ }^{4}$, Anderson \\ Cardoso Sakuma ${ }^{5}$, Leandro Andrade Pegoraro ${ }^{6}$, Luiz Pereira Ramos ${ }^{7}$
}

${ }^{1}$ Aceito para publicação no $3^{\circ}$ Trimestre de 2014

2 Mestranda em Bioenergia na Universidade Federal do Paraná- UFPR, valfcavalcanti@gmail.com

${ }^{3}$ Mestranda em Ciência e Tecnologia Ambiental na Universidade Tecnológica Federal do Paraná- UTFPR, lealbrunaa@hotmail.com

${ }^{4}$ Professor do Departamento Acadêmico de Química e Biologia na Universidade Tecnológica Federal do Paraná- UTFPR, mrealprado@ utfpr.edu.br

5 Doutorando em Engenharia Mecânica na Universidade Federal do Paraná, Anderson.sakuma.tecpar@gmail.com

${ }^{6}$ Doutorando em Engenharia Mecânica e de Materiais na Universidade Tecnológica Federal do Paraná- UTFPR, eandropegoraro@gmail.com

7 Professor do Departamento de Química na Universidade Federal do Paraná- UFPR, luiz.ramos@ufpr.br

\section{Resumo}

O presente trabalho visou obter a biomassa liofilizada da microalga Chlorella vulgaris, cultivada em fotobiorreatores de placas planas, e avaliar seu potencial de produção de ésteres alquílicos por transesterificação in situ. O cultivo foi feito em meio Chu suplementado por emissões geradas na queima do carvão em uma churrascaria. A obtenção da biomassa seca foi feita por eletroflotação, seguida de decantação, congelamento e liofilização, apresentando um rendimento de $0,3397 \mathrm{~g}$ de biomassa seca por L de solução do fotobiorreator submetido à eletroflotação. A síntese de ésteres foi realizada pela transesterificação in situ da biomassa liofilizada tanto pela rota metílica quanto pela etílica, empregando $\mathrm{HCl}_{37 \%} \mathrm{e}$ nhexano. O rendimento, em massa, de produto por biomassa seca foi de $8,73 \%$ para ésteres metílicos e $21,83 \%$ para ésteres etílicos. 
Palavras-chave: tratamento de gases, eletroflotação, biodiesel.

\title{
Cultivation In Flat Plate Photobioreactor And Esters Production By In Situ Transesterification Of Chlorella Vulgaris Microalgae
}

\begin{abstract}
The present work is aimed at obtaining Chlorella vulgaris lyophilized biomass, which were grown in flat plate photobioreactor, and evaluate its potential for alkyl esters production by in situ transesterification. The microalgae were cultivated in Chu medium and supplemented with burning coal emissions generated by a steakhouse. The dry biomass was obtained by electroflotation, followed by decantation and freeze-drying, with a resulting yield of $0.3397 \mathrm{~g} . \mathrm{L}^{-1}$ dry biomass per processed solution in electroflotation. The synthesis of esters was performed by in situ transesterification, using the lyophilized biomass, by methyl and ethyl route, employing $\mathrm{HCl}_{37 \%}$ and hexane. The yield, by mass, of product by dry biomass was $8.73 \%$ for methyl esters and $21.83 \%$ for ethyl esters.
\end{abstract}

Keywords: gas treatment, electroflotation, biodiesel.

\section{Introdução}

Pesquisas em busca por fontes alternativas e/ou complementares para produção de energia estão amplamente relacionadas com a produção de biocombustíveis, mais especificamente o biodiesel. O mesmo é comumente reconhecido como uma alternativa verde ao diesel de petróleo e oriundo de fontes renováveis (BRANCO, 2013).

Os biocombustíveis produzidos das lavouras tornaram-se uma grande controvérsia devido à competição entre alimentos e combustível. Neste contexto, a produção de biocombustível a partir de microalgas é amplamente aceito. Microalgas são capazes de produzir entre 15-300 vezes mais óleo para produção de biodiesel do que as culturas tradicionais, com base na produtividade por área. Além disso, microalgas têm um curto ciclo de colheita (3-15 dias, dependendo da fonte de algas e do processo), permitindo colheitas múltipla ou contínua, com aumento da produtividade de biomassa, quando comparado com plantas de culturas convencionais, que são normalmente colhidas uma ou duas vezes em um ano (ASHOKKUMAR et al., 2014). 
O principal método de produção do biodiesel é a transesterificação. Neste processo, um mol de triacilglicerol reage com três mols de álcool, usualmente o metanol ou o etanol, na presença de um catalisador, que pode ser homogêneo, heterogêneo ou enzimático. A razão molar (RM) estequiométrica de álcool e óleo na transesterificação é de 3:1 (três mols de álcool para um mol de óleo), porém, um amplo excesso de álcool, usualmente 6:1 ou 12:1, é utilizado para deslocar o equilíbrio químico a fim de maximizar a produção de ésteres graxos (RAMOS et al., 2011).

Segundo Menezes et al. (2013), a fim de reduzir o custo da produção do biodiesel de microalgas e aumentar o rendimento em ésteres metílicos de ácidos graxos, para essa biomassa se utiliza a transesterificação in situ (ou direta), na qual a extração e a transesterificação ocorrem simultaneamente numa única etapa. O óleo extraído das microalgas apresenta alto índice de acidez (LEMÕES, 2011) e devido ao conteúdo em ácidos graxos livres nos lipídeos das microalgas, a catálise ácida é considerada viável como rota de síntese para conversão à monoésteres alquílicos (CARVALHO JUNIOR, 2010).

A poluição atmosférica tem se tornado um dos maiores problemas ambientais após a revolução industrial. Com esta, além dos problemas do aquecimento global e de problemas respiratórios, ainda encontram-se os relacionados ao odor produzido por compostos voláteis (MIKAMI, 2011). O sequestro de gases causadores do aquecimento global tem sido pauta de inúmeros projetos em que organismos fotossintetizantes absorvem dióxido de carbono e dissolvem-no em biomassa. Microalgas possuem aparato fotossintético para desempenhar este sequestro (VIEIRA, 2011).

Neste contexto, uma churrascaria investiu na implantação de um sistema biológico para o tratamento das emissões atmosféricas geradas pela queima do carvão. O sistema consiste de dois fotobiorreatores de placas planas contendo microalgas, para onde a fumaça captada da chaminé é direcionada e injetada. Essas microalgas, através de seu metabolismo em presença de luz, utilizam como nutrientes componentes presentes na fumaça, removendo assim compostos causadores do odor (TÖWS, 2013). Como consequência, ocorre a geração de biomassa de microalgas que podem ser utilizadas na produção de biodiesel.

O objetivo deste trabalho foi o de avaliar a obtenção de biomassa liofilizada da microalga Chlorella vulgaris nestes fotobiorreatores de placas planas, bem como o seu potencial de produção de ésteres alquílicos por transesterificação in situ.

\section{Materiais e Métodos}

Revista Brasileira de Energias Renováveis, v. 3, p. 244- 254, 2014 


\section{Obtenção da Biomassa de Microalga}

A microalga Chlorella vulgaris foi cultivada em dois fotobiorreatores de placas planas, instalados na laje de uma churrascaria de Curitiba-PR, em meio de cultivo Chu, utilizando luz natural e sob injeção de emissões atmosféricas, provenientes da queima do carvão, captadas da chaminé do estabelecimento.

A capacidade dos fotobiorreatores é de $510 \mathrm{~L}$ cada um. No entanto, o volume utilizado foi de somente $400 \mathrm{~L}$, pois, quando cheios completamente, produzem muita espuma, extravasando pela parte superior.

O inóculo de microalgas foi preparado a partir de uma quantidade de $10 \%$ de solução de microalgas, considerando o volume utilizado no fotobiorreator, ou seja, $40 \mathrm{~L}$ de solução de microalgas para um volume de $360 \mathrm{~L}$ de meio Chu. O inóculo foi realizado no dia 10 de janeiro de 2014 e, a partir daí, o volume foi sendo completado com água potável sempre que os níveis da coluna de água estavam baixos. No entanto, não foi realizado o controle relacionado à concentração de células, ou microalgas, no volume adicionado, o que prejudica o desenvolvimento de uma curva de crescimento da microalga no sistema.

A coleta foi realizada 139 dias após a inoculação. A biomassa formada no fotobiorreator 1 foi separada do meio de cultivo por eletroflotação, em um sistema desenvolvido por Michelon (2013). O sistema é constituído por uma câmara eletrolítica - com capacidade de $60 \mathrm{~L}$, uma válvula de escoamento, instalada a $5 \mathrm{~cm}$ da base do recipiente, e dois eletrodos de alumínio fixados no fundo do recipiente. Os eletrodos foram conectados a uma fonte modelo OS-5000, operando em uma corrente contínua podendo variar de 0 a 4 Amperes e uma faixa de tensão fixada a 32 Volts. A eletrólise efetuou a separação da biomassa em suspensão de forma física - pela geração de microbolhas - e por meio de reações químicas - formação de hidróxido de alumínio.

Foram realizadas 6 bateladas de 60 L, com recirculação do líquido clarificado para o fotobiorreator. O concentrado de microalgas foi acondicionado em galões de plástico para transporte. A biomassa coletada foi quantificada, homogeneizada e armazenada em refrigerador, sendo mantida em repouso por $24 \mathrm{~h}$ para decantação e remoção do excesso de água. Após, foi transferida para copos plásticos de $40 \mathrm{~mL}$ de capacidade, congelada e liofilizada. A biomassa liofilizada foi pesada e mantida sob refrigeração.

\section{Obtenção dos Ésteres Alquílicos}


Os ensaios foram realizados no Laboratório de Pesquisa Relacionada à Biomassa e Bioenergia (LAPREBB) da Universidade Tecnológica Federal do Paraná (UTFPR), Campus Ecoville, Curitiba-PR.

Com a microalga liofilizada, foram realizados os ensaios para a obtenção de ésteres alquílicos, através do método de transesterificação in situ, descrita por Lewis (2000), utilizando uma mistura de transesterificação contendo um álcool, um catalisador ácido e um solvente. O método foi adaptado para uma maior quantidade de biomassa, visando uma maior produção de ésteres.

Em triplicata, 0,6 $\mathrm{g}$ da biomassa liofilizada da microalga Chlorella vulgaris foram introduzidos em um erlenmeyer de $250 \mathrm{~mL}$ com tampa, seguida da adição de $90 \mathrm{~mL}$ da mistura de transesterificação, recém preparada, álcool (metanol ou etanol):HCl37\%:n-hexano 10:1:1 (v/v/v). Os frascos foram tampados e mantidos em estufa pré-aquecida a $60{ }^{\circ} \mathrm{C}$, durante 90 minutos, sem agitação. Passado este tempo, os frascos foram retirados da estufa, resfriados em banho de gelo até a temperatura ambiente e seu conteúdo foi filtrado sob vácuo para a remoção da microalga pobre.

O meio reacional filtrado foi transferido para um funil de separação de $500 \mathrm{~mL}$. Foram adicionados $30 \mathrm{~mL}$ de água desmineralizada para promover a formação de fases e três porções de $60 \mathrm{~mL}$ da mistura extratora n-hexano:clorofórmio 4:1 (v/v). O sistema foi agitado levemente e deixado em repouso por 30 min. Observou-se a formação de um sistema trifásico, constituído por uma fase orgânica (superior) contendo ésteres e solventes, uma fase glicerínica (intermediária) e uma fase aquosa (inferior) contendo os demais subprodutos da reação. As fases aquosa e glicerínica foram escoadas pela torneira do funil em um mesmo recipiente. A fase orgânica foi recolhida pelo topo e reservada em um erlenmeyer de $250 \mathrm{~mL}$.

A fim de remover a coloração esverdeada ocasionada pelo arraste do pigmento clorofila das microalgas e obter um produto com menos impurezas, a fase orgânica contendo os ésteres foi submetida a um teste de purificação com carvão ativado em pó, em leito fluidizado. Foi adicionado $1 \mathrm{~g}$ de carvão ativado em pó à fase orgânica obtida, agitado manualmente, seguido de repouso de $4 \mathrm{~h}$. O carvão foi removido por filtração em papel de filtro faixa preta.

A remoção do excesso de solvente foi feita em evaporador rotativo, em banho-maria $\left(85^{\circ} \mathrm{C} ; 40 \mathrm{rpm}\right)$. $\mathrm{O}$ destilado foi transferido para um béquer de massa conhecida (P1). O produto foi levado à estufa $\left(60{ }^{\circ} \mathrm{C}\right)$, para a evaporação do solvente residual, até atingir peso constante (P2). A massa de produto foi determinada pela diferença entre P2 e P1. O 
rendimento foi definido como sendo a razão entre a massa de produto (mg) e a massa inicial de biomassa liofilizada $(\mathrm{g})$.

\section{Resultados e Discussão}

Obtenção da biomassa

A solução de microalgas presente nos fotobiorreatores apresentava uma coloração verde-escura, acusando a presença de elementos fotossintetizantes no sistema.

Durante a eletroflotação, foi possível observar o escape de pequenas bolhas geradas na eletrólise. O equipamento possui uma tubulação transparente conectada lateralmente, de onde foi possível acompanhar o acúmulo de microalgas na superfície (Figura 1).

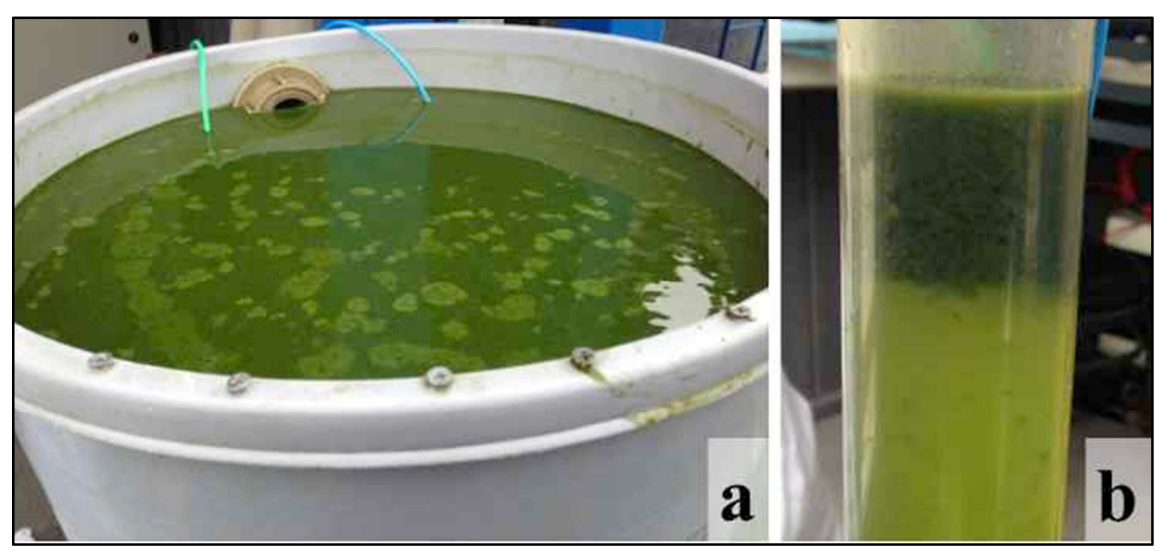

Figura 1 - Eletroflotação: (a) escape de microbolhas; (b) acúmulo de microalgas na superfície do equipamento.

Dos 360 L de solução do fotobiorreator 1 submetidos à eletroflotação, foram coletados 12,384 L de concentrado de microalgas, ou seja, 3,44 \% do volume processado. Lembrando que ocorre a recirculação do líquido clarificado ao fotobiorreator ao final de cada batelada, o que reduz a concentração de células para a batelada seguinte.

A eletroflotação demonstrou ser um método prático e eficiente para a concentração de biomassa microalgal. Porém, após o acondicionamento do concentrado nos galões plásticos, foi observado que a biomassa acumulava-se no fundo após alguns minutos em repouso, revelando a presença de um elevado teor de água na parte superior. Houve uma preocupação em retirar a máxima quantidade de água possível, a fim de agilizar o processo de liofilização. Este material foi deixado em repouso para decantar sob refrigeração por $24 \mathrm{~h}$. 
Após este tempo, foi possível remover 6,630 L de água, ou seja, 53,54\% em volume referente ao total concentrado na eletroflotação.

Ao final da liofilização foram obtidos $122.29 \mathrm{~g}$ de biomassa seca da microalga Chlorella vulgaris. Um rendimento de $0,3397 \mathrm{~g}$ de biomassa seca por L de solução do fotobiorreator submetido à eletroflotação. Vieira (2011) obteve um rendimento de 0,4307 g. $\mathrm{L}^{-1}$ de Chlorella sp. cultivada em fotobiorreator de bancada, em meio Watanabe e suplementado com gás de um incinerador de produtos sólidos tóxicos. Pereira (2013) conseguiu valores de 0,451 g.L-1 de biomassa a partir de um mix de microalgas com predominância do gênero Scenedesmus sp. em meio Chu suplementado com $\mathrm{CO}_{2}$. Logo, o rendimento de biomassa seca apontado neste estudo encontra-se abaixo do encontrado na literatura, podendo ser otimizado por meio de um estudo mais detalhado da curva de crescimento da microalga.

O estudo relacionado à curva de crescimento da microalga $C$. vulgaris para este sistema de cultivo não foi realizado devido à falta de controle da concentração de células no momento da inoculação. Através deste estudo teria sido possível determinar as fases de crescimento da microalga e identificar e corrigir fatores que possam interferir na produção de biomassa nos fotobiorreatores. O conhecimento da fase de crescimento exponencial (log) ajuda a determinar o período em que o sistema apresenta maior densidade de células antes de atingir a fase estacionária, podendo ser realizado um planejamento para definir os dias de coleta, o que poderia gerar maior rendimento de biomassa.

\section{Obtenção dos Ésteres Alquílicos}

Ao final da reação de transesterificação in situ, o conteúdo dos frascos apresentavam uma forte coloração esverdeada, em virtude da possível extração e arraste do pigmento clorofila das microalgas. Na etapa de extração, foi possível observar a formação de um sistema bifásico após a adição da água. Em seguida, com a adição da mistura nhexano:clorofórmio 4:1 (v/v), e deixando o volume total em repouso, foi possível verificar a formação de três fases bem distintas sendo formadas no funil de separação (Figura 2). 


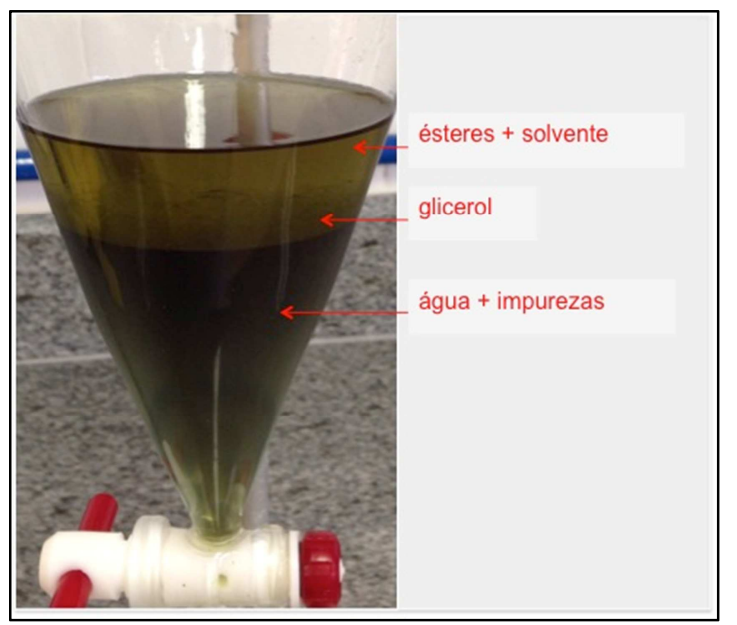

Figura 2 - Sistema trifásico formado na extração.

Após a extração, a fase orgânica contendo os ésteres foi submetida à clarificação por adsorção, obtendo-se um líquido transparente e amarelo-claro (Figura 3). A justificativa para este procedimento é baseada na presença de pigmentos e demais impurezas geradas e/ou arrastadas pelo solvente na transesterificação in situ de microalgas, que podem interferir na determinação do rendimento de produto ( $\mathrm{mg}_{\text {produto }}$ : $\mathrm{g}_{\text {biomassa liofilizada }}$ ) após a secagem, mascarando o resultado final.

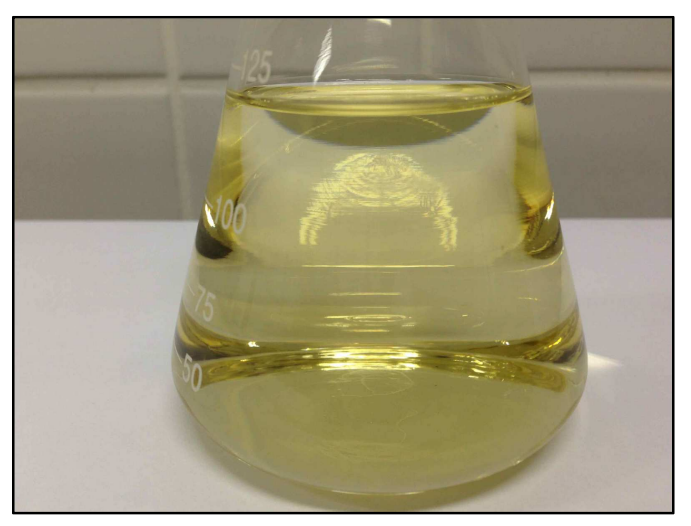

Figura 3 - Fase orgânica após a clarificação com carvão ativado.

Com relação ao rendimento de produto final contendo os ésteres, foram obtidos, em média, 87,32 $\mathrm{mg}_{\text {produto }}: \mathrm{g}_{\text {biomassa liofilizada }}$ para ésteres metílicos e 218,32 $\mathrm{mg}_{\text {produto }}$ : $\mathrm{g}_{\text {biomassa_liofilizada }}$ para ésteres etílicos $(8,73 \%$ e $21,83 \%$, respectivamente).

Cavalcanti et al. (2013) realizaram um estudo semelhante de produção de ésteres alquílicos a partir da biomassa liofilizada de uma cultura mista, apresentando rendimentos de 
117,93 e 89,64 $\mathrm{mg}_{\text {produto }}$ : g biomassa liofilizada para ésteres metílicos e etílicos $(11,79 \%$ e 8,9 \%, respectivamente). Os resultados atuais, empregando Chlorella vulgaris estão abaixo do obtido com a cultura mista via rota metílica mas, obteve valores muito superiores com relação à rota etílica. Salientando que no estudo anterior, empregando a cultura mista, não foi realizada a clarificação para a remoção das impurezas, o que torna o resultado da transesterificação in situ a partir da C. vulgaris ainda mais satisfatório.

Silva-Baumgärtner (2011) obteve como rendimento, para a microalga Scenedesmus $s p ., 61,79$ e 60,74 mg de éster/g de biomassa para etanol e metanol, respectivamente, ou seja, $6,18 \%$ e $6,07 \%$, na temperatura de $60^{\circ} \mathrm{C}$, utilizando hexano como solvente. Em um estudo mais recente, Silva-Baumgartner et al. (2013) verificaram que a síntese de ésteres da biomassa de Spirulina platensis mostrou melhor resultado utilizando etanol e hexano, em temperatura de $45^{\circ} \mathrm{C}$, obtendo valores de rendimento acima de $70 \mathrm{mg} / \mathrm{g}$.

Segundo Silva-Baumgärtner (2011), diferença nas reações de transesterificação/esterificação in situ entre espécies ocorrem, possivelmente, devido às diferenças na estrutura celular entre as espécies de microalgas. Logo, os resultados aqui adquiridos estão de acordo com os encontrados na literatura.

\section{Conclusão}

A partir deste estudo foi possível concluir que a microalga Chlorella vulgaris, cultivada em fotobiorreatores de placas planas e suplementadas pelas emissões geradas pela queima de carvão, apresentam potencial para serem utilizadas na produção de ésteres alquílicos. Porém, é necessário realizar um estudo da curva de crescimento das microalgas neste sistema a fim de se atingir maiores rendimentos de biomassa.

\section{Agradecimentos}

À administração da Devon's Grill por permitir o acesso aos fotobiorreatores.

À equipe do TECPAR (Instituto de Tecnologia do Paraná) pela realização da coleta e por todas as informações fornecidas.

À Coordenação de Aperfeiçoamento de Pessoal de Nível Superior (CAPES) pela concessão da bolsa de estudos para a realização deste trabalho.

\section{Referências}

Revista Brasileira de Energias Renováveis, v. 3, p. 244- 254, 2014 
ASHOKKUMAR, V.; RENGASAMY, R.; DEEPALAKSHMI, S.; SIVALINGAM, A.; SIVAKUMAR, P. Mass cultivation of microalgae and extraction of total hydrocarbons: A kinetic and thermodynamic study. Fuel. 119, p.308-312, 2014.

BRANCO, K. B. Z. F. Estudo da transesterificação in situ da microalga Scenedesmus sp. visando a síntese de ésteres para produção de biodiesel. 2013, 75p. Dissertação (Mestrado em Engenharia Química) - Departamento de Engenharia Química, Universidade Estadual de Maringá, Maringá, 2013.

CARVALHO JUNIOR, R. M. Desenvolvimento e análise energética do processo de obtenção do biodiesel de microalgas por metanólise in situ. 2010, 85 p. Dissertação (Mestrado em Engenharia) - Programa de Pós-Graduação em Engenharia Mecânica e de Materiais, Universidade Federal do Paraná, Curitiba, 2010.

CAVAlCANTI, V. F.; LEAL, B. E. S.; TRAMONTINI, M. P.; ANZE, M. H. N.; PRADO, M. R.; SAKUMA, A. C.; PEGORARO, L. A. Avaliação qualitativa do uso de microalgas de um sistema biológico para tratamento de emissões atmosféricas na produção de biodiesel. In: $8^{\circ}$ Cong. Int. de Bioenergia, 2013, São Paulo. Anais... São Paulo: Porthus Eventos, 2013. 1 CD-ROM.

LEMÕES, J. S. Síntese de ésteres graxos de Chlorella sp. utilizando os processos de extração transesterificação e transesterificação in situ. 2011, 56p. Dissertação (Mestrado em Química Tecnológica e Ambiental) - Universidade Federal do Rio Grande, Rio Grande, 2011.

LEWIS, T.; NICHOLS, P. D.; MCMEEKIN, T. A. Evaluation of extraction methods for recovery of fatty acids from lipid-producing microheterotrophs. Journal of Microbiological Methods. v.43, n.2, p.107-106, 2000.

MENEZES, R. S.; LELES, M. I. G.; SOARES, A. T.; BRANDÃO P. I.; FRANCO, M.; ANTONIOSI FILHO, N. R.; SANT'ANNA, C. L.; VIEIRA, A. A. H. Avaliação da potencialidade de microalgas dulcícolas como fonte de matéria-prima graxa para a produção Revista Brasileira de Energias Renováveis, v. 3, p. 244- 254, 2014 
de biodiesel. Quim. Nova, v.36, n.1, p.10-15, 2013.

MICHELON, L. K.; Estudo de alternativa para separação de microalgas por eletroflotação. 2011, 64p. Trabalho de conclusão de curso (Graduação) - Curso Superior de Tecnologia em Processos Ambientais, Departamento Acadêmico de Química e Biologia, Universidade Tecnológica Federal do Paraná, Curitiba, 2013.

MIKAMI, W., R.; Avaliação da eficiência de um sistema biológico para tratamento de emissões atmosféricas. 2011, 60p. Trabalho de conclusão de curso (Graduação) - Curso Superior de Tecnologia em Processos Ambientais, Departamento Acadêmico de Química e Biologia, Universidade Tecnológica Federal do Paraná, Curitiba, 2011.

PEREIRA, A. B. Produção de biomassa e de lipídeos por cultivo misto de microalgas suplementado por CO2. 2013, 109p. Dissertação ( Mestrado em Engenharia Química) Departamento de Engenharia Química, Universidade Federal do Paraná, Curitiba, 2013.

RAMOS, L. P.; SILVA, F. R.; MANGRICH, A. S.; CORDEIRO, C. S. Tecnologias de produção de biodiesel. Rev. Virtual Quím., v.3, n.5, p. 285-405, 2011.

SILVA-BAUMGÄRTNER, T. R. D. S. Cultivo e extração de óleo das microalgas Scenedesmus sp. e Spirulina sp. para a síntese de ésteres visando a produção de biodiesel. 2011, 124p. Tese (Doutorado em Engenharia Química) - Departamento de Engenharia Química, Universidade Estadual de Maringá, Maringá, 2011.

SILVA-BAUMGARTNER, T. R. D. S.; BURAK, J. A. M.; BAUMGARTNER, D.; ZANIN, G. M.; ARROYO, P. A. Biomass production and ester synthesis by in situ transesterification/esterification using the microalgae Spirulina platensis. International Journal of Chemical Engineering. V.2013, Article ID 425604, 7 pages, 2013.

TÖWS, M. Identificação de riscos à segurança do trabalhador na operação de remoção de odores - caso de uma churrascaria em Curitiba. 2013, 51p. Monografia (Especialização em Engenharia de Segurança do Trabalho) - Departamento Acadêmico de Construção Civil, Universidade Tecnológica Federal do Paraná, Curitiba 2013. 
VIEIRA, D. B. Cultivo de Chlorella sp. em fotobiorreator suplementado com gás de incineração de resíduos sólidos perigosos e avaliação de sequestro de dióxido de carbono para produção de biomassa. 2011, 92p. Dissertação (Mestrado em Engenharia Agrícola) Programa de Pós-graduação em Engenharia Agrícola, Universidade Federal de Viçosa, Viçosa, 2011. 